\title{
IMPROVEMENTS IN NUCLEAR-DENSITY CONE PENETROMETER FOR NON-HOMOGENEOUS SOILS
}

\author{
Muthusamy Karthikeyan ${ }^{i}$, Thiam Soon Tanii), Mamoru Mimura ${ }^{\text {iii), }}$ Mitsugu Yoshimura ${ }^{\text {iv) }}$ \\ and Choon Peng TeEv)
}

\begin{abstract}
In Singapore, the use of clays from marine dredging and land-based construction activities as fill for land reclamation provides a solution to the problem of disposal while turning such unwanted soils into material of economic value. A major problem with such fill is the formation of very high degree of heterogeneity in the ground. The characterization of such ground at different stages of land reclamation works poses a major challenge as many traditional in-situ tests which provide point values are based on solutions derived assuming the ground is a continuum. A major site characterization program was carried out as part of a research project. The Nuclear-Density Cone Penetrometer is employed for site investigation to measure the continuous changes in density together with other usual cone parameters. The tests have been conducted at various stages of land reclamation works. In the present paper, the problems faced in marine based investigations associated with the use of an existing Double Probe Nuclear-Density Cone Penetrometer are briefly discussed and this limitation has led to the development of a new Single Probe NuclearDensity Cone Penetrometer which is the main focus of this paper. The wet density profiles obtained from the Single Probe Nuclear-Density Cone Penetrometer are compared with the double probe and the comparison shows a very good agreement.
\end{abstract}

Key words: land reclamation, lumpy fill, natural radioactivity, nuclear-density cone penetrometer, wet density (IGC: C3/D3)

\section{INTRODUCTION}

Dredging works in the coastal areas and excavations in urban areas produce large quantities of unwanted soils in Singapore. As there are no land fills in Singapore, the disposal of such soils pose an almost intractable problem because of the very large volume involved. The use of such soils as fill for Singapore continued growing appetite for land reclamation, provides a sensible alternative and is now implemented in the 1500 hectares Pulau Tekong reclamation project off the northern eastern coast of Singapore.

For such innovative use of unwanted soils to be cost effective, they were dumped directly into the reclamation site. The resulting fill is highly heterogeneous, characterized by a structural matrix formed by large lump of soils, with large voids between them, the inter-lump voids. These inter-lump voids can be filled with small clay lumps, slurry and/or water, as shown in Fig. 1. A major challenge in this project is the characterization of such type of "lumpy" fill. A review of the literature suggests

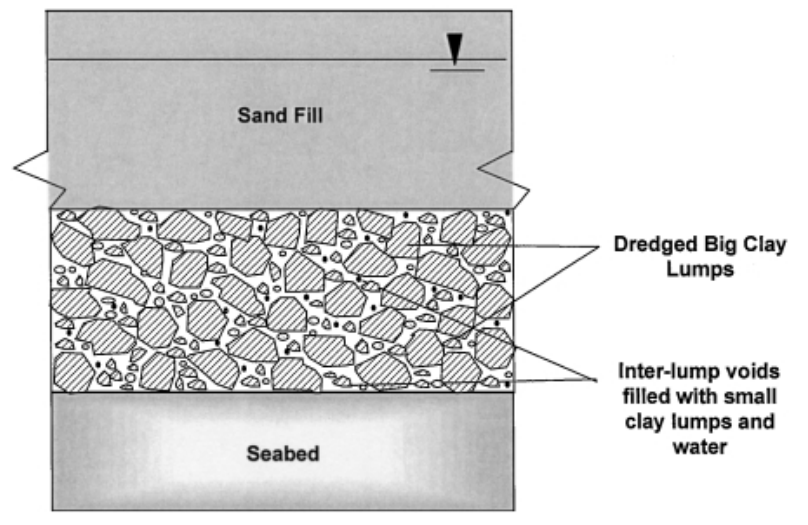

Fig. 1. Schematic profile of reclamation with clay lumps (after Karthikeyan et al., 2004)

that there is little information on the behavior of the lumpy fill in the field, except surface settlements (Casagrande, 1949; Whitman, 1970; Hartlen and Ingers, 1981; Bo et al., 2001).

i) Visiting Scholar, Department of Civil Engineering, National University of Singapore, Singapore.

Associate Professor, ditto.

iii) Associate Professor, Disaster Prevention Research Institute, Kyoto University, Uji, Japan (mimura@geotech.dpri.kyoto-u.ac.jp).

iv) General Manager, Soil and Rock Engineering Co. Ltd., Toyonaka, Japan.

v) Surbana International Consultants Pte Ltd., Singapore.

The manuscript for this paper was received for review on June 8, 2006; approved on September 10, 2006.

Written discussions on this paper should be submitted before September 1, 2007 to the Japanese Geotechnical Society, 4-38-2, Sengoku, Bunkyo-ku, Tokyo 112-0011, Japan. Upon request the closing date may be extended one month. 
For a lumpy fill, retrieval of undisturbed samples is near impossible especially at the early state when interlump voids are big. Most in-situ tests are based on the response of a continuum to a simple probe such as a cone penetrometer or a flat plate (dilatometer). The existence of a loose lumpy matrix with large voids makes meaningful interpretation of the obtained point values very difficult. One parameter that can complement the usual cone parameters to provide a deeper insight to the ground condition is the density of the fill.

A Nuclear-Density Cone Penetrometer (ND-CP) has been shown to be able to measure reliably in-situ wet density of a soil (Shibata et al., 1992; 1993; 1994; Mimura et al., 1995; 1999; Mimura and Shrivastava, 1998; Shrivastava and Mimura, 1998). This cone penetrometer will provide information of the density of a small volume around the probe, over and above the usual cone parameters of cone resistance $\left(q_{\mathrm{c}}\right)$, sleeve friction $\left(f_{\mathrm{s}}\right)$ and pore pressure $\left(u_{2}\right)$.

These researchers have focused on the use of the extensively ND-CP in naturally deposited clayey and sandy formations. Since then, this tool was used to profile the ground in a reclamation project in Singapore, in which the fill is formed by clay lumps and is highly heterogeneous (Karthikeyan et al., 2001, 2004; Dasari et al., 2006). The interpretation of the results from such Nuclear-Density cone penetration test (ND-CPT) is challenging (Karthikeyan, 2005) but when done properly, can produce meaningful results.

The existing design of the Nuclear-Density Cone Penetrometer requires two probing for every single location; first, to obtain the background count of naturally occurring gamma photons and then to measure the actual nuclear density (RI) count. The natural radioactive count (background; BG) is inevitable and needs to be subtracted from the total count measured to give a count that is better correlated to the density to be measured. The natural background count itself is also related to the soil that is being studied and this issue is also examined in this paper. This requirement for two probings causes a number of serious practical difficulties in the investigation when the surface of the fill is below sea-level (submarine condition) and the tests need to be carried out from barges. In searching a solution to these practical difficulties, a new Nuclear-Density Cone Penetrometer was designed which requires only a single probing. This paper will discuss the issues involved in this development.

\section{DESCRIPTION OF NUCLEAR-DENSITY CONE PENETRATION TEST (ND-CPT)}

The Nuclear Density Cone Penetrometer used in the present study is based on the design of Shibata et al. (1993). Figure 2 shows major components of the NuclearDensity Cone Penetrometer. The lower part of the cone houses various sensors to measure the three typical cone parameters, namely, cone resistance $\left(q_{\mathrm{c}}\right)$, sleeve friction $\left(f_{\mathrm{s}}\right)$ and pore pressure $\left(u_{2}\right)$. The size of the lower part conforms to the standards recommended by the Interna-

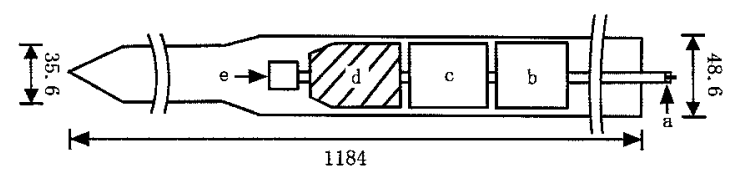

Fig. 2. Diagram of Nuclear-Density Cone Penetrometer: (a) Cable leading to data collection system, (b) Preamplifier, (c) Photomultiplier tube, (d) Lead (Pb) shield, (e) ${ }^{137}$ Cs gramma-ray source: All dimensions are in millimeters (after Shibata et al., 1993)

tional Society for Soil Mechanics and Foundation Engineering (ISSMFE, 1989) for cone penetration testing, namely the diameter is $35.6 \mathrm{~mm}$, the apex angle is $60^{\circ}$, the base area is $10 \mathrm{~cm}^{2}$ and the area ratio is 0.75 . A porous ceramic filter is located just behind the cone tip. The total length of the shaft housing the sensors is 258 $\mathrm{mm}$. After this, the shaft tapers outwardly at an angle of $15^{\circ}$. The tapered portion of the shaft is $49 \mathrm{~mm}$ long and beyond this, the shaft has a constant diameter of 48.6 $\mathrm{mm}$ and extends for a total length of $896 \mathrm{~mm}$. This upper part houses the radioisotope source, the detector, and a preamplifier. The gamma ray source used in the construction of the Nuclear-Density Cone Penetrometer is the Cesium $\left(\mathrm{Cs}^{137}\right)$ isotope (primary source of radiation is a 3.7 MBq) which has a half-life of 37.6 years, and the detector is sodium iodide activated with thallium (NaI (TI)) scintillator mounted on a photomultiplier tube. The length of the NaI scintillation detector is $10.2 \mathrm{~mm}$. The separation distance between the source and the center of the gamma detector is $255 \mathrm{~mm}$.

The ND-CPTs were performed according to the procedure for standard piezocone penetration tests, as specified by British Standard, BS 5930:1999. During testing, the ND-CP was pushed into the ground at a rate of approximately $1-2 \mathrm{~cm} / \mathrm{s}$ and cone resistance $\left(q_{\mathrm{c}}\right)$, sleeve friction $\left(f_{\mathrm{s}}\right)$, pore pressure $\left(u_{2}\right)$, RI count and background (BG) count were recorded continuously. The detailed description and working procedure of ND-CPT was reported in Shibata et al. (1993) and calibration issues have also been discussed by Shibata et al. (1993) and Dasari et al. (2006).

\section{LAND RECLAMATION USING BIG CLAY LUMPS}

As part of the construction of the bunds surrounding the area to be reclaimed, large dredged clay lumps of up to about $8 \mathrm{~m}^{3}$ in volume were excavated using clam-shell grabs to form a trench for the construction of a sand key. A typical clay lump dredged from the seabed is shown in Fig. 3. The physical properties of these stiff clay lumps consists of about 5\% sand, 55\% silt and $40 \%$ clay sized particles. These stiff clay lumps have a natural moisture content of $60 \%$, liquid limit of $77 \%$ and plastic limit of $36 \%$. These dredged clay lumps are placed in a barge and transported to a reclaimed site, where the lumps are discharged on to the seabed up to 1-2 $\mathrm{m}$ below the sea level. This depth is needed to cater for the draught of the barge dumping the lumps. Sand is then used to cap the fill and to provide the surcharge to accelerate the consolida- 


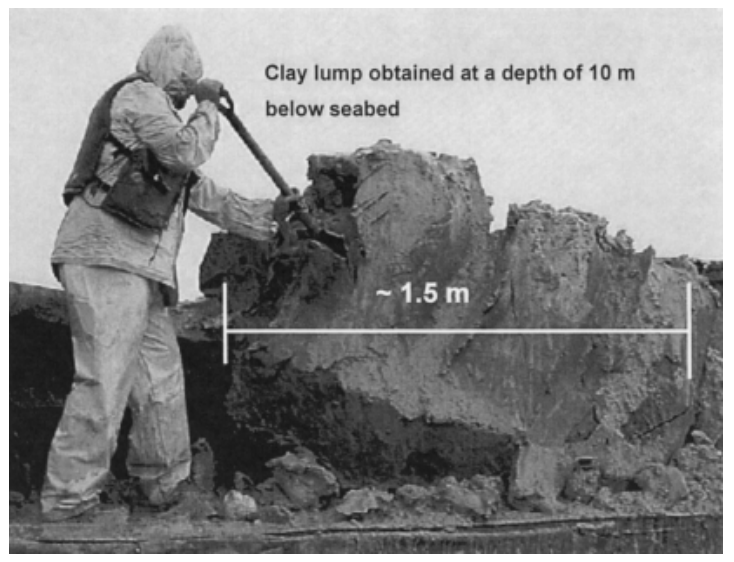

Fig. 3. A typical big clay lump obtained using clam-shell grab

tion. A schematic section of the reclamation site with dredged clay lumps and sand surcharge is shown in Fig. 1. During the early stages of reclamation, there would be large voids between the big dredged clay lumps and these inter-lump voids (void between lumps) could be partly filled with small lumps, slurry and/or water. The key problem with a lumpy fill is the very high degree of heterogeneity due to a very porous structural matrix formed by the lumps (Karthikeyan et al., 2004). The characterization of such a ground at different stages of land reclamation works poses a major challenge, and the ND-CP has proven to be an effective tool to characterize such a ground (Dasari et al., 2006).

\section{SITE INVESTIGATION}

The field works to be described were carried out at the 1500 hectares Pulau Tekong Reclamation project off the northeast coast of mainland Singapore. The project began in 1999 and is still ongoing. Three field pilot tests (TA 1, TA 2, and TA 3) were conducted in this project. The site investigations were carried out using a NuclearDensity Cone Penetrometer. Thus far, the state of the lumpy fill at two different stages has been profiled. The first stage is immediately after placing the dredged materials in the reclamation area up to $-3 \mathrm{mCD}$ (metre above chart datum; chart datum is taken as mean sea level) and the second stage is immediately after dumping the capping sand, up to $+4 \mathrm{mCD}$. The third stage will be at the end of consolidation, which has not been reached yet.

In Stage 1, as the surface of fill is below sea level, NDCPTs were performed using a Marine Cone Penetration System, as shown in Fig. 4. The control unit and the hydraulic power unit were placed on a barge. A hydraulic penetration system, which was mounted on steel frame or tower, was lowered on to the surface. The reaction force was provided by the dead weight of the steel tower. The barge is equipped with a four-point anchor mooring system to secure the barge in position and to maintain its stability during operations. In Stage 2, land is already formed above the sea level and thus a conventional CPT

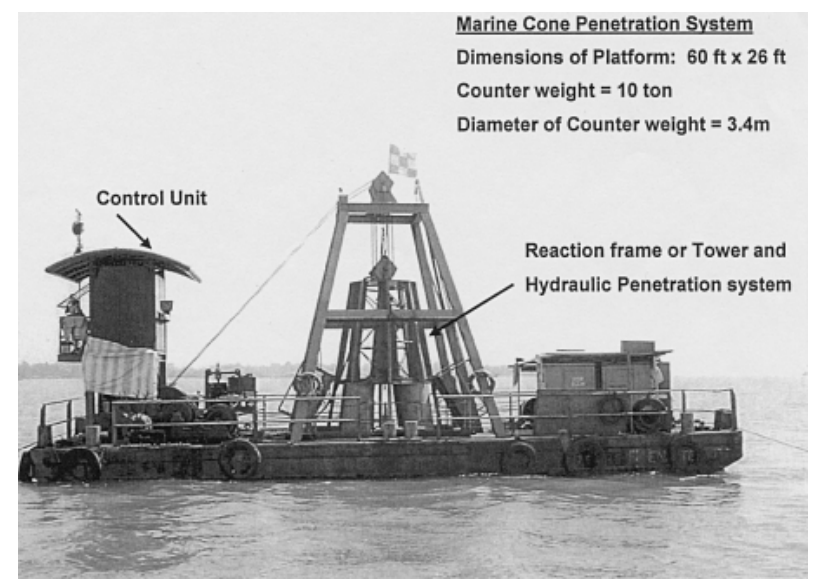

Fig. 4. Photographic view of the Marine Cone Penetration System used in Stage 1

crawler was used to carry out the ND-CPTs.

\section{FIELD INVESTIGATION LAYOUT}

In this paper, the results from one of the 3 field pilot tests (TA 2) will be discussed in greater detail. The pilot test area (TA 2) is $100 \mathrm{~m}$ in length and $100 \mathrm{~m}$ in width. The clay lumps were placed directly on the seabed which is about -13 to $-14 \mathrm{mCD}$ by bottom-opening barges to form an $8 \mathrm{~m}$ to $9 \mathrm{~m}$ thick lumpy fill layer from June to August 2002. 120 numbers of marine ND-CPTs were conducted from August to November 2002 (Stage 1). Subsequently, $7 \mathrm{~m}$ of sand was placed in several lifts up to $+4 \mathrm{mCD}$ over a period of 10 months. Then, another 120 numbers of ND-CPTs were conducted from December 2003 to March 2004 (Stage 2) with the intention to be over the same location as in Stage 1. However, it was impossible to ensure that the ND-CPTs were carried out in exactly the same locations because of inevitable surveying setting-out errors of about $\pm 0.5 \mathrm{~m}$. While such a small deviation usually does not pose any problem in a site investigation, in this project, this is a problem due to the lumpy nature of the fill.

The investigation plan carried out at TA 2 for Stage 1 and Stage 2 is shown in Fig. 5, which consists of a small dense grid set within a big grid. The big grid is $99 \mathrm{~m} \times 100$ $\mathrm{m}$ and the small grid is $10 \mathrm{~m} \times 11 \mathrm{~m}$. The small dense grid is highlighted as 'A' in Fig. 5. The big grid consists of 110 ND-CPTs and the small dense grid has 10 ND-CPTs within a $10 \mathrm{~m} \times 11 \mathrm{~m}$ area, an extremely closely spaced arrangement. This arrangement was designed to provide adequate information to characterize a representative volume of lumpy fill and also to provide sufficient idea of the variation.

\section{PROBLEMS FACED IN SUB-MARINE INVESTIGATION}

Problems in the sub-marine investigation in Stage 1 come mainly from the fact that the current design of the Nuclear-Density Cone Penetrometer requires two prob- 


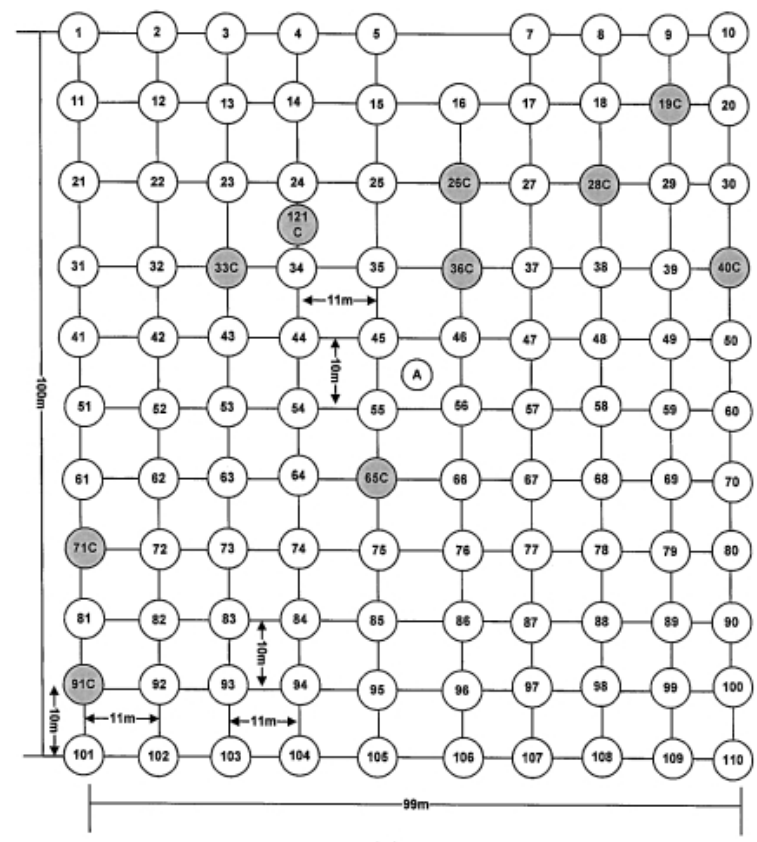

(a)

Fig. 5(a). Layout of ND-CPT in site investigation at TA 2 (Stages 1 and 2)

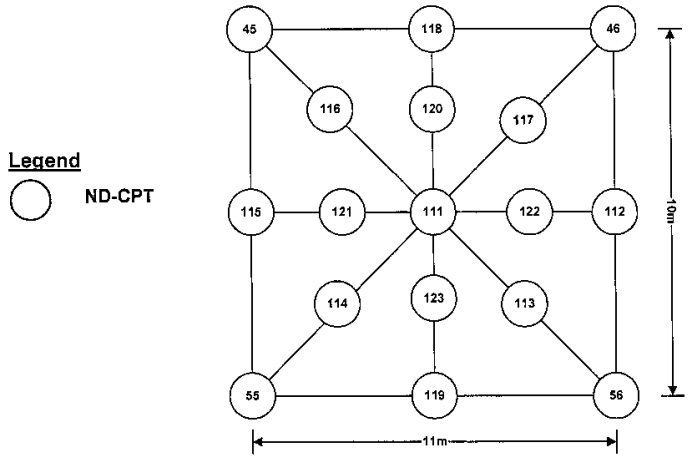

(b)

Fig. 5(b). Detailed ND-CPT layout at location ' $A$ ' in the site investigation

ing for every single measuring point, first to obtain the background count of natural radiation and then the actual nuclear density (RI) count, so as to obtain the net gamma-ray count to determine the actual nuclear density measurement. The background count is measured using a cone which contains only a detector and no gamma source.

Figure 6 shows the typical background count profiles with depth obtained for a number of natural soils. It can be seen that for these natural soils, there are little fluctuations with depth. If the soil is homogeneous and the variation in the background count profile is negligible within a test site, then double probes are not required, as errors from slight variation in location will be negligible. Figure 7 shows the background and RI count profiles obtained for the lumpy fill site at locations RI 45, RI 111, RI 115, RI 116, RI 118 and RI 120, which are in the small dense grid, shown in Fig. 5. Although all the six ND-
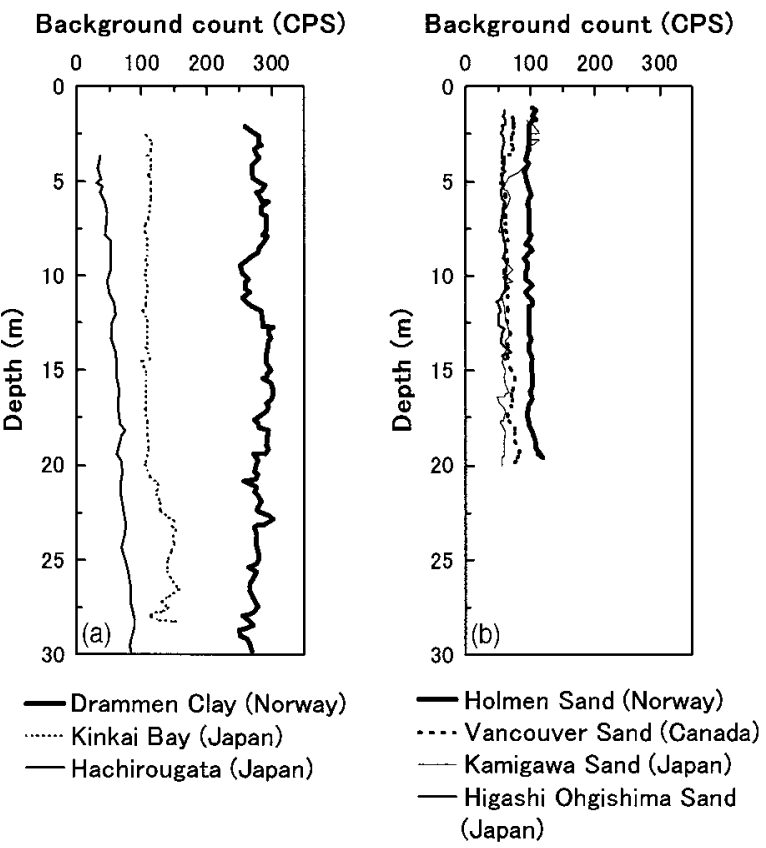

Fig. 6. Typical background count profiles obtained for homogeneous soils: (a) clay deposit and (b) sandy deposits (Nobuyama, 2000)
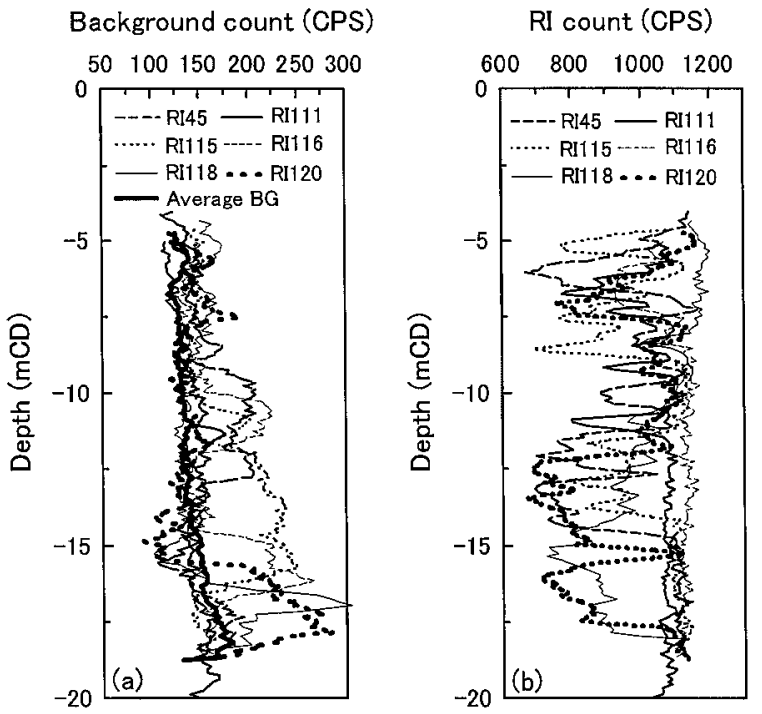

Fig. 7. Typical profiles obtained for highly heterogeneous lumpy fill: (a) Background count and (b) RI count

CPTs are very closely spaced within a $5.0 \mathrm{~m} \times 5.5 \mathrm{~m}$ square grid, very significant variation in RI and background count profiles can be observed, a consequence of the fact that the lumpy fill is highly heterogeneous. With this degree of variation in the background count, the use of any averaged background count profile is likely to be problematic. Figure 7(a) shows an average background count profile obtained for the above six profiles. If the average background count profile is used together with the actual RI counts shown in Fig. 7(b) to determine the wet density, then an error of about $10 \%$ is observed in the estimated wet density as shown in Fig. 8 for locations RI 45 and RI 115. To reduce the error in such a highly heterogeneous lumpy fill site, it is necessary to carry out 

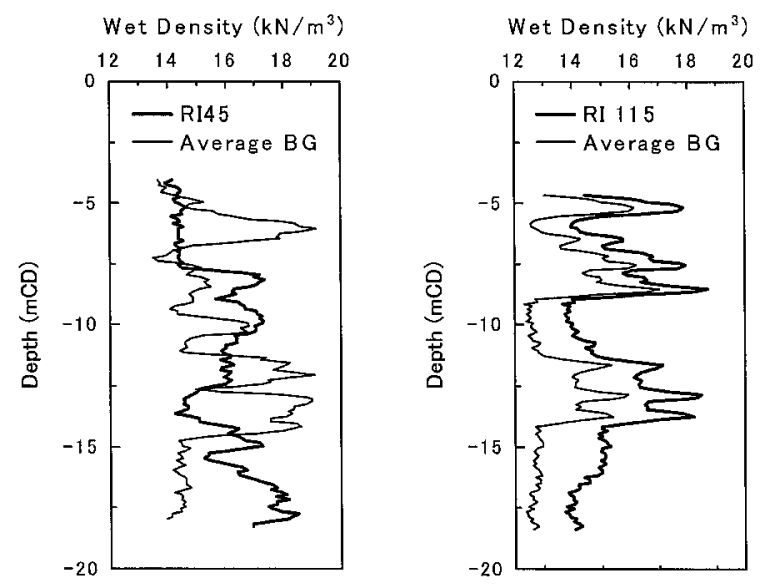

Fig. 8. Comparison of estimated wet density using actual measured background count and average background count

two probings at every single measuring point, and the two probings need to be located precisely at the same hole.

In a sub-marine investigation (Stage 1), it is very difficult, time consuming and expensive to ensure that the two probes conducted at two different timings are pushed through exactly the same hole due to operational difficulties. In reality, the variation in the two different probings ranges from $0.15 \mathrm{~m}$ to $1.5 \mathrm{~m}$. The data shown in Fig. 7 show very large variation even with small variation in location. This high sensitivity to location will affect seriously the accuracy of the measured density for the highly heterogeneous fill encountered here.

Before discussing the new development, at this juncture, it is important to have a better understanding of the natural radioactivity in soils. Therefore, an investigation was carried out to evaluate the factors influencing the natural radioactivity (background count; $B G$ ) in soils and this is discussed next.

\section{INFLUENCE OF NATURAL RADIOACTIVITY (BACKGROUND COUNT)}

Radioactive elements are found naturally in air, water and soil. There is nowhere on Earth that we cannot find natural radioactivity. The amount of radioactivity level (background count) in soil varies greatly depending on the soil type, mineral makeup, density of materials and its geological history (Eisenbud, 1987). To evaluate the variation of the background count in soil, laboratory experiments were carried out using the calibration chamber. One of the controlling factors is the size of the laboratory calibration chamber. Based on the theory of gamma scattering and neutron methods (Homilius and Lorch, 1958; Olgaard, 1965), the "measuring volume" around a source was found to be about $30 \mathrm{~cm}$ in radius. Based on experimental results, Karthikeyan (2005) deduced that the maximum radius of the influence zone for the ND-CP used in the present study is about $23.6 \mathrm{~cm}$, as shown in Fig. 9, and it was found that the radius of influence zone decreases with increasing wet density of the material.

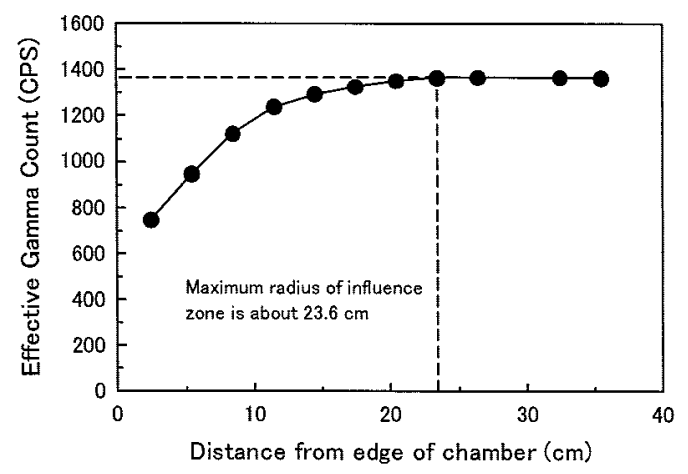

Fig. 9. Maximum radius of the influence zone of ND-CPT measurement in water (after Karthikeyan, 2005)

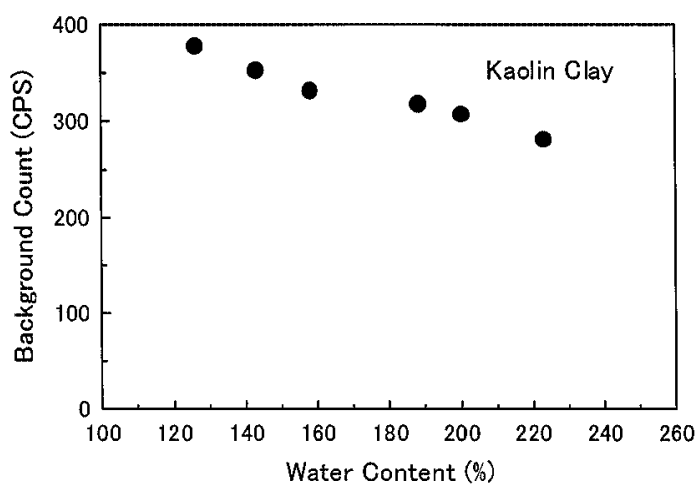

Fig. 10. Laboratory results showing variation in the BG count value with various water content of soil

Therefore, a stainless steel chamber of diameter 700 $\mathrm{mm}$ and height $1000 \mathrm{~mm}$ was used to carry out the experiment. In the first series of tests, only kaolin clay was used and slurries of different water contents were prepared. The physical properties of the kaolin clay showed that it consists of about $87 \%$ clay fraction and $13 \%$ silts. The calibration chamber was filled with slurry and the background count was measured using a dummy cone, in which only the detector is placed at the centre of the calibration chamber to measure the BG count. The BG counts for clay slurries with water content ranging from $125 \%$ to $225 \%$ were measured and the results are shown in Fig. 10. This figure shows that the BG count value decreases with increasing water content of kaolin clay.

Next, the BG counts from field tests are examined. Figure 11 shows the variations in the BG count with wet density for clayey and sandy soils. These BG counts data were obtained from Nobuyama (2000), for different soil types namely, Kinkai Bay clay, Hachirogata clay, Holmen sand, Higashi Ohgishima sand and Vancouver sand. The data from Pulau Tekong and Punggol Timor are obtained as part of the present research work. From Fig. 11(a), it can be seen that for clayey soils, the BG count varies depending upon the physical properties and its depositional history of the sediment. The BG count for naturally deposited clayey soils varies from 30 to 250 cps (counts per second). The intensity of natural gamma 

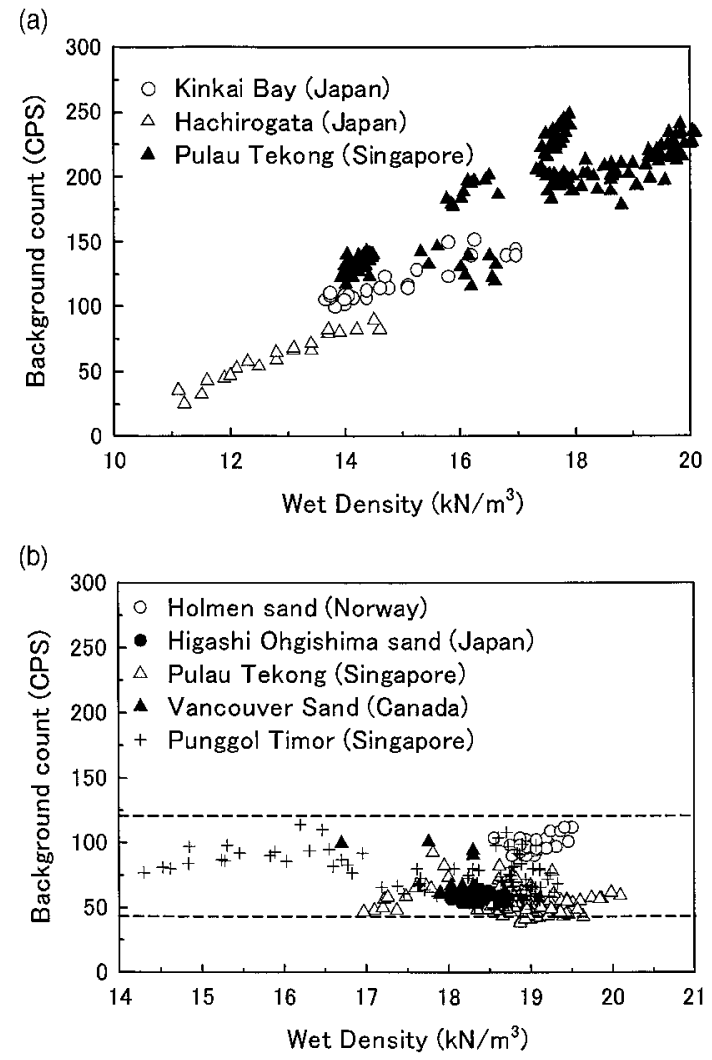

Fig. 11. Typical variation in the BG count with wet density for different soils from the field studies: (a) clayey soils and (b) sandy soils

ray (BG) mainly depends on the concentration of radioactive minerals present in soil, such as potassium (K). As the content of the radioisotope minerals varies depending upon the soil types, hence the value of BG count is also different for each clayey soils. Figure 11(a) also shows a rough correlation between the background count and wet density, which could be a useful preliminary profiling indicator. However, for the sandy soils, the BG count values vary within a relatively narrow band from 40 to $120 \mathrm{cps}$, as can be seen in Fig. 11(b). The BG count for sandy soils also does not vary much with its wet density.

Clearly, the intensity of natural radioactivity (background count; BG) depends on wet density of soil, thus the background count profiles are also useful to classify the soil type when other more conclusive information is not available. As a general trend at the same densities, the background count profile is weak in sand as compared with clay and thus it can be used as a rough guide to identify the boundary between clay and sand strata. These results also confirm the necessity of taking into account the background count for accurate determination of wet density in characterization of a highly heterogeneous lumpy fill. Towards this purpose, the existing double probe ND-CP needs to be improved to measure both the RI count and BG count with one probing.

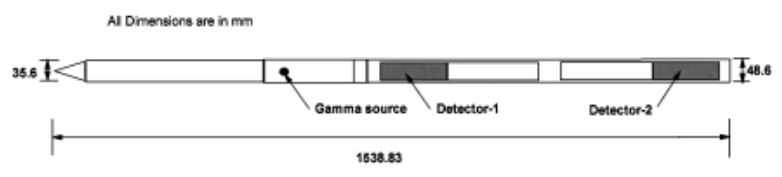

Fig. 12. Diagram of Single Probe Nuclear-Density Cone Penetrometer (All the dimensions are in millimeters)

\section{IMPROVEMENTS IN NUCLEAR-DENSITY CONE PENETROMETER}

A Single Probe Nuclear-Density Cone Penetrometer is developed by modifying the double probe where the gamma-ray section is extended so as to insert an additional detector that is outside of the gamma-ray zone emitting from the source. With this, the cone is able to measure both the background and actual RI count during the same probing, thus removing the need to do two probings, a real challenge when carrying out such characterization under sub-marine condition.

\section{Description of Single Probe ND-CP}

Figure 12 shows major components of the Single Probe Nuclear-Density Cone Penetrometer (ND-CP). The lower part of the new cone is similar to the old ND-CP where it houses various sensors to measure the usual cone parameters, namely, cone resistance $\left(q_{\mathrm{c}}\right)$, pore pressure $\left(u_{2}\right)$, and the sleeve friction $\left(f_{\mathrm{s}}\right)$. The upper part of the cone section is extended so as to insert an additional detector to measure the naturally occurring gamma photons. This upper part houses the radioisotope source, and two detectors. Detector-1 is used to measure the actual nuclear density (RI) count and Detector-2 is used to obtain the background count of naturally occurring gamma photons.

\section{Separation Distance between Detector-1 and 2}

In this new development, the important issue is to ensure that the separation distance between the two detectors (Detector-1 and -2) is sufficient, so that the additional detector (Detector-2) is able to measure the background count accurately without being influenced by the gamma-ray source that is placed in the cone. Therefore, experimental investigations were carried out to determine the minimum separation distance needed between the two detectors. Two different sets of laboratory experiments were conducted using a stainless steel calibration champer of diameter $600 \mathrm{~mm}$ and height 2000 $\mathrm{mm}$. In the first set of experiments, the calibration chamber was filled with water and the upper part of the cone with the radioisotope source and detector units were kept inside at the centre of the calibration chamber. In the second set, experiments were conducted without the radioisotope source unit but only the detector was kept inside at the centre of the chamber. In both experiments, the detector is moved up vertically inside the cone shaft with the help of a pull-up motor and at the same time, the gamma counts detected were recorded continuously.

Figure 13 shows the results obtained for the measured 


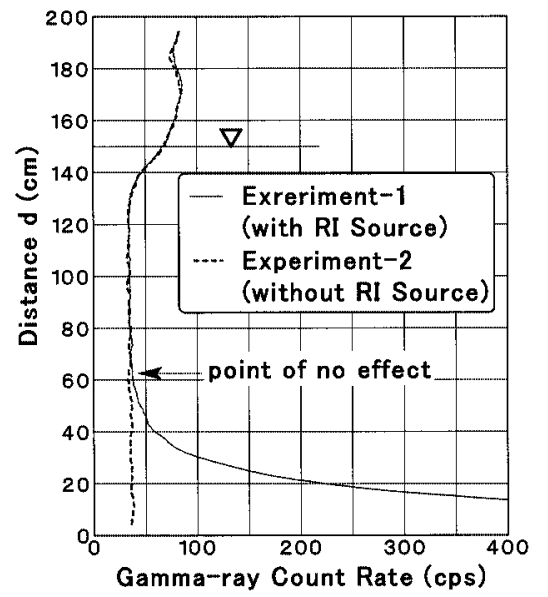

Fig. 13. Relationship between the gamma-ray count rate versus distance for two laboratory experiments

gamma counts versus distance in the two different sets of experiments. This figure shows that there are significant differences in measured gamma counts for a depth of about $600 \mathrm{~mm}$, clearly suggesting that the minimum separation distance required between the two detectors is about $600 \mathrm{~mm}$. Subsequently, this calibrated separation distance is used for the design of a single probe NuclearDensity Cone Penetrometer. Another issue that needs to be investigated is the applicability of field calibration chart obtained for the Double Probe to a Single Probe Nuclear-Density Cone Penetrometer which is discussed in a later section.

\section{Depth Corrections}

Because of the fact that different sensors and detectors are placed at different locations along the probe, there is a need to adjust the depths so as to be able to produce the parameters at the same depth. For the Single Probe ND$\mathrm{CP}$, the measurement center for the cone is considered at the cone resistance sensor just like in the original ND-CP and then the other sensors readings are adjusted accordingly. The depth corrections for pore pressure $(0.04 \mathrm{~m})$, sleeve friction $(0.11 \mathrm{~m})$ and RI Count $(0.60 \mathrm{~m})$ remain the same as in the original ND-CP while the BG Count data needs to be shifted up by $1.20 \mathrm{~m}$.

\section{Detector Efficiency Ratio}

As described earlier, in the single probe ND-CP, two detectors were housed in the same probe to measure both the actual nuclear density (RI) count and the background (BG) count of naturally occurring gamma photons simultaneously, whereas, in the double probe ND-CP, the RI count and BG count are measured by the same detector but in two separate probings. The counting efficiency (numbers of counts recorded per unit time) of these two detectors in the Single Probe ND-CP are not similar and it was found that the ratio between Detector-1 and Detector-2 is 1.0353 . This difference in detector efficiency must be accounted for while calculating the effective gamma count for the Single Probe ND-CP. The effective gamma count is calculated as below:

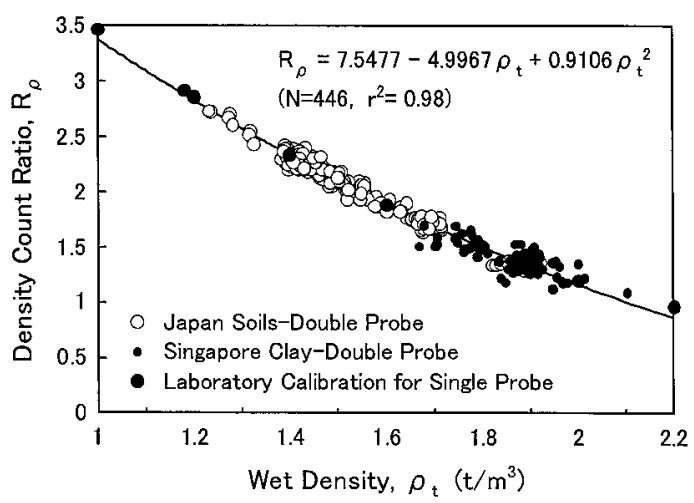

Fig. 14. Improved calibration chart obtained for Single Probe Nuclear-Density Cone Penetrometer

Effective gamma count $=$ RI Count $-1.0353 *$ BG Count

\section{Calibration of the Single Probe Nuclear-Density Cone Penetrometer}

The newly developed Single Probe Nuclear-Density Cone Penetrometer needs to be calibrated before it can be used to obtain an accurate relation between the wet density to the count rate ratio. For this purpose, the calibration chamber was filled with water and the ND-CP was placed at the centre of the chamber to measure both RI Count and BG Count. Similarly another configuration was made with Sodium Silicate chemicals with a wet density of $14 \mathrm{kN} / \mathrm{m}^{3}$ instead of water. The wet densities of these liquids are known and the calibration charts relating the density to the count rate ratio were then obtained. These two data are incorporated into the field calibration chart obtained for Double Probe NuclearDensity Cone Penetrometer, as shown in Fig. 14. There is a unique and consistent trend between the count rate ratio and the wet density regardless of whether the ND$\mathrm{CP}$ is single or double probing. Finally, the applicability of the calibration charts in Fig. 14 against field data is discussed next.

\section{COMPARISON OF SINGLE AND DOUBLE PROBE ND-CPT}

The development of the single probe is to overcome the need for two probing in the same hole in a marine based investigation. As a brand new tool, its performance needs to be compared against the double probe device which has been extensively calibrated and used to date. The comparison of the double and single probe ND-CP was carried out when land is formed above the sea level. This removes any ambiguity about the position and it is possible to ensure that the two probings conducted at different timings are pushed through exactly the same hole. Out of a total of 120 tests in Stage 2, 10 tests were used for this purpose. The locations are 19C, 28C, 33C, 36C, 40C, 65C, 71C, 91C, 109C and 121C in Fig. 5. 10 numbers of double probe ND-CPTs were conducted 

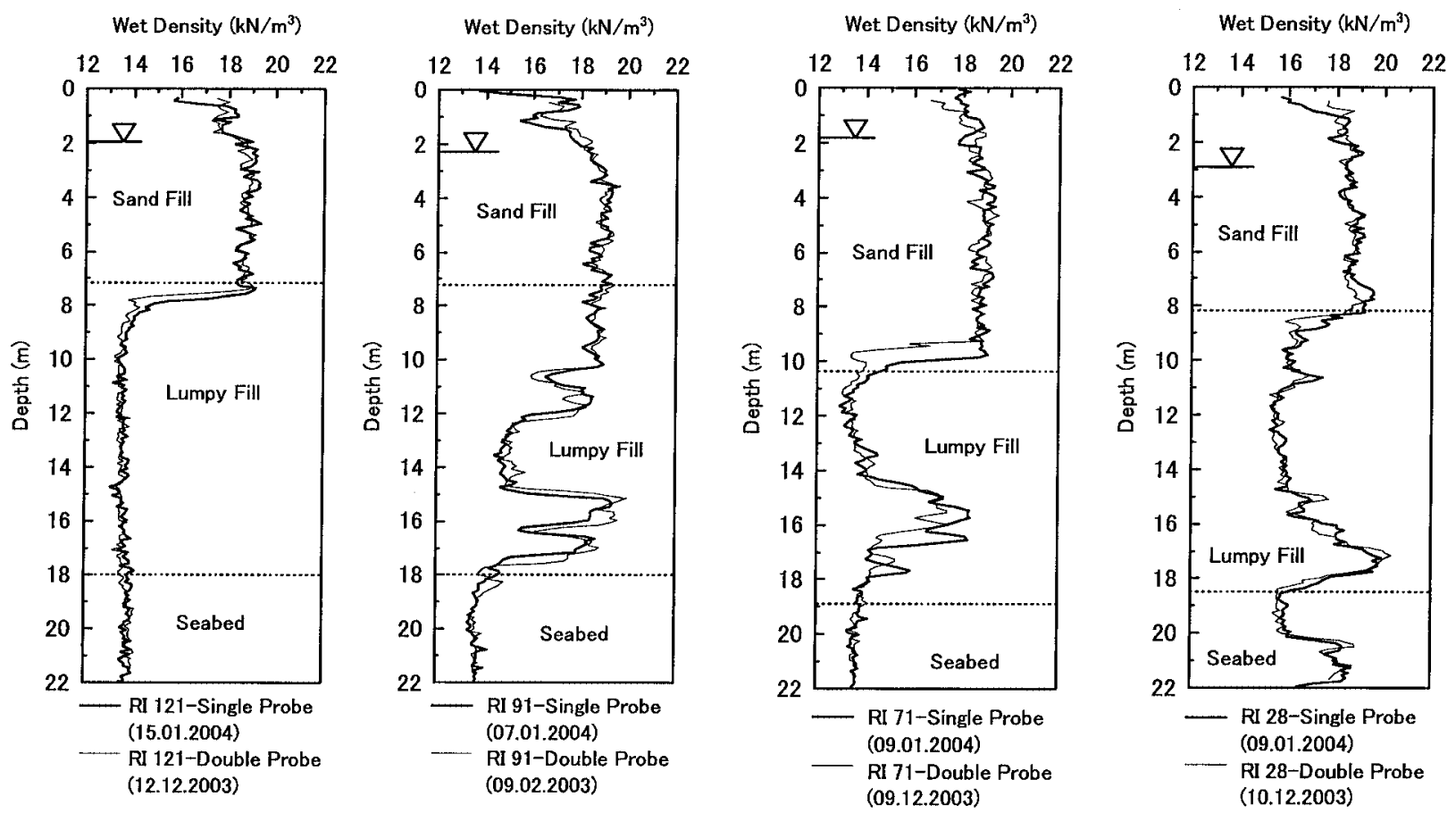

Fig. 15. Comparison of wet density profiles measured by the Double Probe ND-CPT with the Single Probe

from 4th December to 12th December 2003. Unfortunately, the single probe ND-CPT could not be performed immediately after completing the double probe tests due to some practical problems encountered. The problems arose mainly because the increase in the length of the single probe ND-CP to accommodate the additional detector led to bending when the cone encountered a dense sandy layer above the ground-water table. It took about a month to modify the cone structure. To avoid potential damages to the newly modified equipment, a hole was pre-drilled about $6 \mathrm{~m}$ from the ground level for the remaining ND-CPT locations in Stage 2. The loss of information for the first $6 \mathrm{~m}$ of the sandy layer is not critical to this study as the aim is to profile the highly heterogeneous lumpy fill below. The single probe NDCPTs using the new cone were conducted in the same hole from 5th January 2004 to 15 th January 2004. As this was carried out one month after the double probe tests, during this time, some additional settlement was observed in the newly reclaimed land. As the settlement was measured, these readings were used for adjusting the depth of the measured wet density profiles accordingly.

The wet density profiles obtained from the double probe ND-CPT are compared with the single probe NDCPT, using the same calibration chart and the results show very good agreement, as shown in Fig. 15. The results from only four out of the $10 \mathrm{ND}-\mathrm{CPT}$ are shown in Fig. 15 for illustration. This result also means that the separation distance between the two detectors is sufficient, so that Detector-2 is able to measure the background accurately. As a further result, there is a very good agreement in the measured wet density profiles for both the sand fill at the top and the soft clayey seabed at the bottom. However, there are some small differences in the spikes between the single probe and double probe for the highly heterogeneous lumpy fill in between the sand and seabed. The small variation in wet density spikes may be attributed to the average measurement of ND-CPT within the measuring volume. In a ND-CPT, the measuring sphere of the radioactive source is about 23.6 $\mathrm{cm}$ in radius, and thus the density measured reflects the average around the central point of the radioactive source and detector configuration. In addition, it is also necessary to carry out averaging or filtering of wet density profiles measured by ND-CPT to reduce statistical fluctuations. In spite of these small differences, it is clear that the single probe ND-CPT has performed very well in measuring the wet density profiles.

One of the main advantages of this newly developed Single Probe ND-CP is that it eliminates the need for double probing and the uncertainties that are involved in ensuring that both probings are along the same location, a real challenge in a sub-marine environment. The use of a single probe device in a sub-marine investigation is a significant improvement to the design of ND-CP.

\section{CONCLUSIONS}

Nuclear-Density Cone Penetrometer was extensively used to evaluate the early state of the lumpy fill formed by the dredged clay lumps. In this paper, problems faced while performing ND-CPTs in sub-marine investigation were highlighted. Experiments conducted in soils to investigate the influence of natural radioactivity (background count) showed that the natural radioactivity (background count) of soils greatly depends on the wet density of soil. Thus the background count profiles are also useful to provide a rough classification of the soil 
type when other more conclusive information is not available. As a general trend at the same densities, the background count profile is weak in sand as compared with clay and thus it can be used as a rough guide to identify the boundary between clay and sand strata. These findings clearly demonstrate the importance of the background count in the characterization of a highly heterogeneous lumpy fill for accurate determination of wet density of soils.

An important contribution in this paper is the development of a new Single Probe Nuclear-Density Cone Penetrometer. This new single probe is developed by modifying the double probe where the gamma-ray section is extended so as to insert an additional detector that is outside of the gamma-ray zone emitting from the source. With this, the cone is able to measure both the background and actual RI count during the same probing. The comparison of the wet density profiles obtained from the double probe and the single probe ND-CPT is conducted when land is formed above the sea level. The measured results from the single probe ND-CPT agree very well with that from the double probe. This implies that the separation distance between the two detectors is sufficient, so that the additional detector is able to measure the background count accurately. This newly developed single probe ND-CP eliminates the need for double probing and the uncertainties that are involved in ensuring that both probings are along the same location, a real challenge in a sub-marine environment. Commercially, this is also important especially in sub-marine measurement where each test is time consuming. This will mean significant cost saving.

\section{ACKNOWLEDGEMENTS}

The authors would like to thank Housing and Development Board, Singapore, Surbana International Consultants Pte Ltd, Singapore, TOA-JDN (PUT) Joint Venture, Singapore and Kiso-Jiban Consultants Co., Ltd, Singapore, for their support during site investigation and laboratory testing. The authors have benefited greatly from the many discussions on the details of ND-CPT with Mr. M. Nobuyama of Soil \& Rock Engineering Co. LTD., Japan. The authors are also grateful to the National Science and Technology Board (NSTB) (Presently known as A* STAR) of Singapore for funding the present research work under grant NSTB/MCE/99/ 003.

\section{REFERENCES}

1) Bo, M. W., Bawajee, R. and Choa, V. (2001): Reclamation using dredged materials, Proc. Int. Conf. Port and Maritime $R \& D$ and Technology, The Maritime and Port Authority of Singapore, 455-461.
2) British Standards Institution (1999): Code of Practice for Site Investigations (BS 5930), British Standards Institution (BSI), London.

3) Casagrande, A. (1949): Soil mechanics in the design and construction of Logan Airport, J. Boston Society of Civil Engineers, 36 (2), 176-205.

4) Dasari, G. R., Karthikeyan, M., Tan, T. S., Mimura, M. and Phoon, K. K. (2006): In-situ evaluation of radioisotope cone penetrometers in clays, Geotech. Test. J., ASTM, 29 (1), 45-53.

5) Eisenbud, M. (1987): Environmental Radioactivity: From Natural, Industrial and Military Sources, Third Edition, Academic Press, 475 .

6) Hartlen, J. and Ingers, C. (1981): Land reclamation using finegrained dredged material, Proc. 10th ICSMFE, Stockholm, 1, 145-148.

7) Homilius, J. and Lorch, S. (1958): On the theory of gamma ray scattering in boreholes, Geophysical Prospecting, VI, 342-364.

8) ISSMFE (1989): International reference test procedure for cone penetration test (CPT), Report of the ISSMFE Technical Committee on Penetration Testing of Soils-TC 16, with References to Test Procedures, Swedish Geotechnical Institute, Linkoping, Information, 7, 6-16.

9) Karthikeyan, M. (2005): Application of radioisotope cone penetrometer to characterize a lumpy fill, $P h$. D Thesis, National University of Singapore, Singapore. 219p.

10) Karthikeyan, M., Dasari, G. R., Tan, T. S., Lam, P. W., Loh, Y. H., Wei, J. and Mimura, M. (2001): Characterization of a reclaimed land site in Singapore, Proc. 3rd Int. Conf. Soft Soil Engineering, Hong Kong, 587-592.

11) Karthikeyan, M., Dasari, G. R. and Tan T. S. (2004): In-situ characterization of land reclaimed using big clay lumps, Can. Geotech. J., 41 (2), 242-256.

12) Mimura, M. and Shrivastava, A. K. (1998): RI-Cone penetrometers experience in naturally and artificially deposited sand, Proc. Ist Int. Conf. Site Characterization-ISC'98, Atlanta, 1, 575-580.

13) Mimura, M., Shrivastava, A. K., Shibata, T. and Nobuyama, M. (1995): Performance of RI cone penetrometers in sand deposits, Proc. Int. Symp. Cone Penetration Testing (CPT'95), 2, 55-60.

14) Mimura, M., Shrivastava, A. K., Shibata, T. and Nobuyama, M. (1999): In-situ measurement of wet density and natural water content with RI-Cone penetrometers, Proc. 5th Int. Symp. Field Measurements in Geomechanics, Singapore, 559-564.

15) Nobuyama, M. (2000): The result of the RI cone penetration tests, NUS Internal Report No. 6004998/264, Soil and Rock Engineering Co., Japan.

16) Olgaard, P. L. (1965): On the theory of the neutronic method for measuring the water content in soil, Danish Atomic Energy Commission Research Establishment, Denmark, Riso Report No. 97.

17) Shibata, T., Mimura, M., Shrivastava, A. K. and Nobuyama, M. (1992): Moisture measurement by neutron moisture cone penetrometer: design and application, Soils and Foundations, 32 (4), 58-67.

18) Shibata, T., Mimura, M. and Shrivastava, A. K. (1993): RI Cone Penetrometer experience in marine clays in Japan, Proc. 4th Canadian Conference on Marine Geotechnical Engineering, 3, 1024-1033.

19) Shibata, T., Mimura, M. and Shrivastava, A. K. (1994): Use of RI cone penetrometer data in foundation engineering, Proc. 13th ICSMFE, New Delhi, 1, 147-150.

20) Shrivastava, A. K. and Mimura, M. (1998): Radioisotope cone penetrometers and the assessment of foundation improvement, Proc. 1st Int. Conf. Site Characterization-ISC'98, Atlanta, 1, 601-606.

21) Whitman, R. V. (1970): Hydraulic fills to support structural loads, J. Soil Mech. Found. Div., ASCE, 96 (SM 1), 23-47. 